\title{
Text Analysis of Beethoven's G Minor Fantasia
}

\author{
Yan Bai \\ Shaanxi Xueqian Normal University, Xi'an Shaanxi, 710061, China
}

Keywords: Beethoven; fantasia; music structure; music form.

\begin{abstract}
G Minor Fantasia (OP.77) created by Beethoven in 1809 is a fantasia created for piano. This work has rich tune changes, involves diversified creation methods, shows Beethoven's abundant music thinking and super-high creation ability and embodies the essence of his piano music language. It integrates Beethoven's styles in each period.
\end{abstract}

\section{Introduction}

After Europe went through Napoleonic wars, establishment of Vienna system, revolution in 1848, bourgeois revolution and reform in 1960s-1970s, capitalism power grew day by day. The development of European capitalism made art pattern change, and music art was gradually liberated from feudalistic constraints and churchly suppression, started to move to the broad social class, more deeply expressed human nature and reflected richer social life. In such situation, the musicians with democratic ideas expressed their dissatisfaction and confusion for the reality as well as their pursuits in music creation to make music development exhibit diversity and national nature.

Grove Dictionary of Music defines fantasia as follows: fantasia has the specific theme and very free composition style, and is full of works of impromptu form and composed of many independent periods. Impromptu form is the main feature of fantasia. Improvisational creation and performance make composers and performers show the most natural emotion for music and also embody their super-high creation skills and rich music connotation. G Minor Fantasia (OP.77) was crated in 1809 for Earl Brunswick. It is composed of many contrast periods. The speed and tonality of each period are not consistent. The speed mark is as follows: from poco adagio to allegro ma nontroppo full of emotions - allegro con brio; after one period, A-flat major adagio turns to presto and enter più presto; then, adagio appears again and B major allegro; after graceful theme variation, enter the end.

\section{Music structure}

The work adopts single movement. The whole music is divided into introduction, Period A, Period B, Period C, Period D and ending. After the slow introduction, the theme full of expressions is revealed. Then, periods of ever-changing melody come like tidewater. From Period D, the periods consist of theme variation mode, and variations of seven periods and eight bars are constructed. Then, scale cadenza repeatedly used by the first period returns to the lento adagio as the perfect ending. This work has many changes in terms of tonality, style, rhythm, texture and speed, so it is a quite wonderful song. It also shows Beethoven's rich music thinking and super-high creation ability.

\subsection{Introduction G minor, $4 \backslash 4$ meters}

In the beginning, two periods of fast $G$ minor descending scale are played with the sufficient volume. Then, slow melody with meditation style is followed to give people a surprise. The score also clearly marks the speed: from Allegro to Poco Adagio. Such material is repeated again, but the second tonality moves to $\mathrm{F}$ minor from $\mathrm{G}$ minor.

\subsection{Period A, B-flat major, $6 \backslash 8$ meters, Allegro ma nontroppo}

This period adopts diphonia and octave chord, and applies the low pitch and triplet performance mode as the accompaniment. The regular sense of rhythm and fluent melody line make the whole 
work own pleasant rural dance song style. Next, the fast ascending arpeggio tone cluster is used as the transition to enter the next period.

\subsection{Period B, D minor, 2/4 meters, Allegro con brio}

Beethoven applied parallel octave, decomposed octave and octave chord as the basic structure of this period. The figure of decomposed octave is alternately performed between the left hand the right hand to show the lively and brilliant atmosphere. The sudden volume change is also one of characteristics of this period.

\subsection{Period C, B minor, 6\8 meters, più presto}

The curtain is lifted by low pitch accompaniment mode of diphonia and decomposed octave. As volume becomes louder and louder, diphonia at the right hand also gradually expands to become octave chord. Then, triplet of broken chord is followed. Hidden melody of both hands continues through third-degree interval relation. The fluctuations of volume and sequence skills are the features of this period.

\subsection{Period D, B major, 2\4 meters, Allegretto}

This period is the largest period in the whole music. Beethoven used a 8-bar theme phrase as the skeleton to make eight different development changes. The materials used in each period are different. Besides, the styles are also diverse. These fully show his super-high improvisation creativity.

\subsection{Ending, B major, $2 \backslash 4$ meters, Tempo primo}

This is the last period of the music. Beethoven did not use new materials, but followed the last music style of the last period. The chord tone was expanded to octave tone. The figure composed of disjunct motion and descending scale at the left hand is given the broader range for development, which makes music momentum grander and more gorgeous. The descending scale appearing again brings out the slow and grand theme melody. Finally, the whole song ended with the inverse scale.

\section{Music form}

IN G Minor Fantasia, the composer applied very rich music language, such as free variation for the theme, fast scale, bright dynamics and speed contrast, explosive stress and diversified texture types. All these form music form features of the fantasia. The features will be explained one by one as follows.

\subsection{Theme variation}

Theme variation is very important in composition. Experienced musicians can often extemporize variations. In particular, the theme with slow rhythm can be improved in the variation process. Mozart's biographer Otto Jan wrote, "Mozart once extemporized one theme of Beethoven. Then, Beethoven immediately created a piece of graceful and complete music. After that, Mozart excitedly said, 'notice this young man. One day, this world will talk about him."' G Minor Fantasia (OP.77) is almost the score written down after improvisation of a small theme.

The theme of G Minor Fantasia (OP.77) is based on the background of triplet, with the dynamic multi-voice chorus of texture theme. It is lyric and full of singing property (from the 157th bar to the 164th bar);

Example 1:

In the first variation of G Minor Fantasia (OP.77), the dotted figure at the right hand and the jumping diphonia figure at the left hand intersect. It is light and joyful (from the $165^{\text {th }}$ bar to the $172^{\text {nd }}$ bar); 


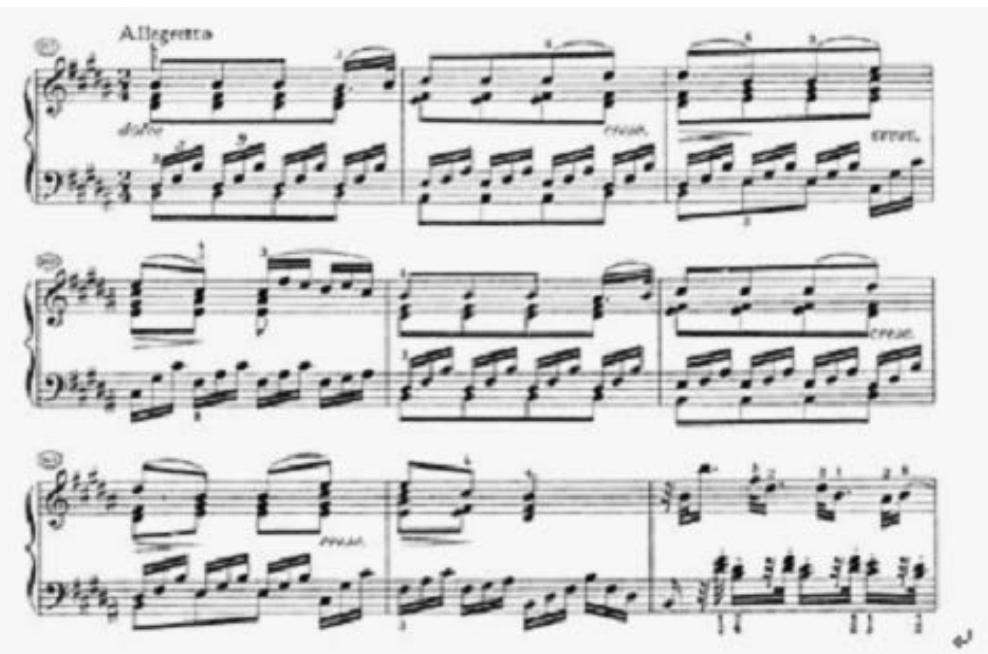

Example 2:
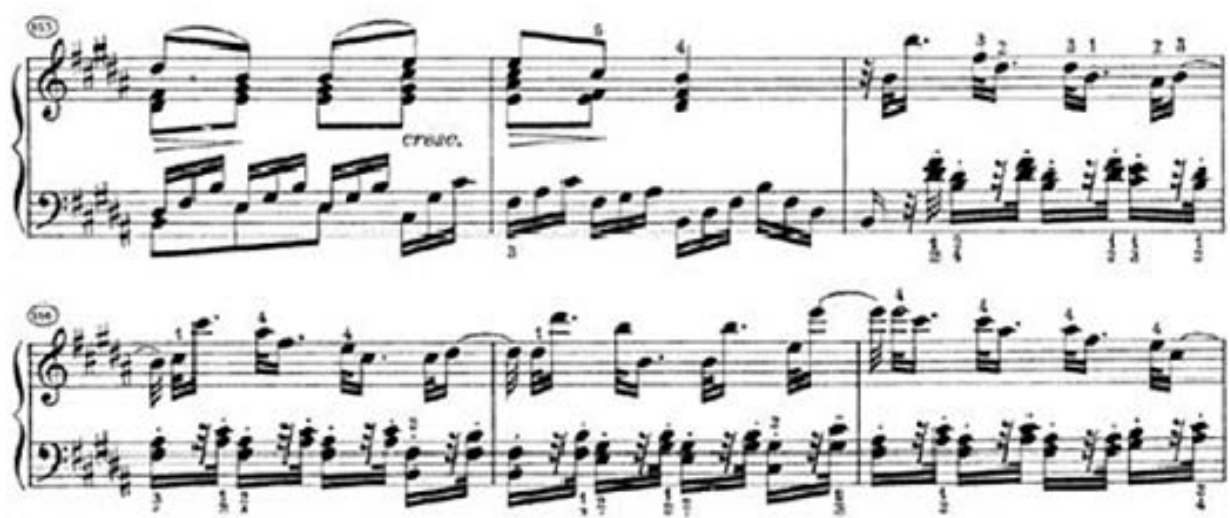

The second variation of G Minor Fantasia (OP.77) is antistrophic for gentle and full timbre at both hands, which forms the bright contrast with the first variation (from the 173rd bar to the 180th bar);

Example 3:
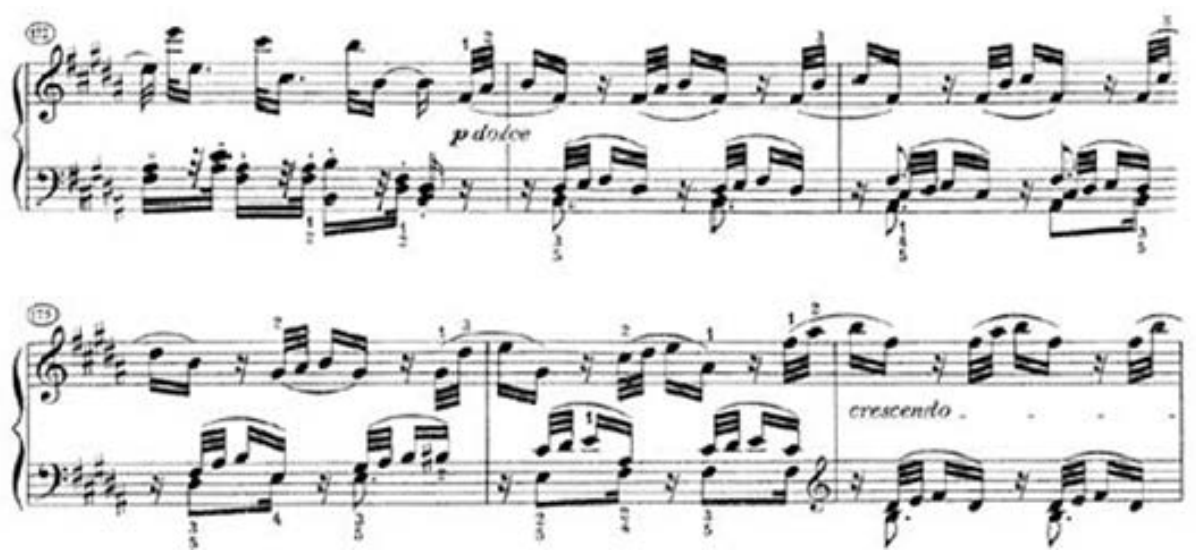

\subsection{Cadenza decorated by scales}

At the beginning of G Minor Fantasia (OP.77), Beethoven boldly applied descending scale similar to the effect of cadenzn which is composed of demisemiquaver, thus presenting the unique music after careful thinking. It seems to tell others Beethoven is speaking now. This plays the bridge role of decoration and connection (from the first bar to the $4^{\text {th }}$ bar)

Example 9:

In OP.77, Beethoven often regarded scale-type transition phrases as the dynamic means. They not just have the lingering charm of Mozart's transition phrase pattern, but also have high rhythm density and large range. Meanwhile, they have the feature of mild, indirect and free expansion, like romantic cadenza (the $221^{\text {st }}$ bar); 


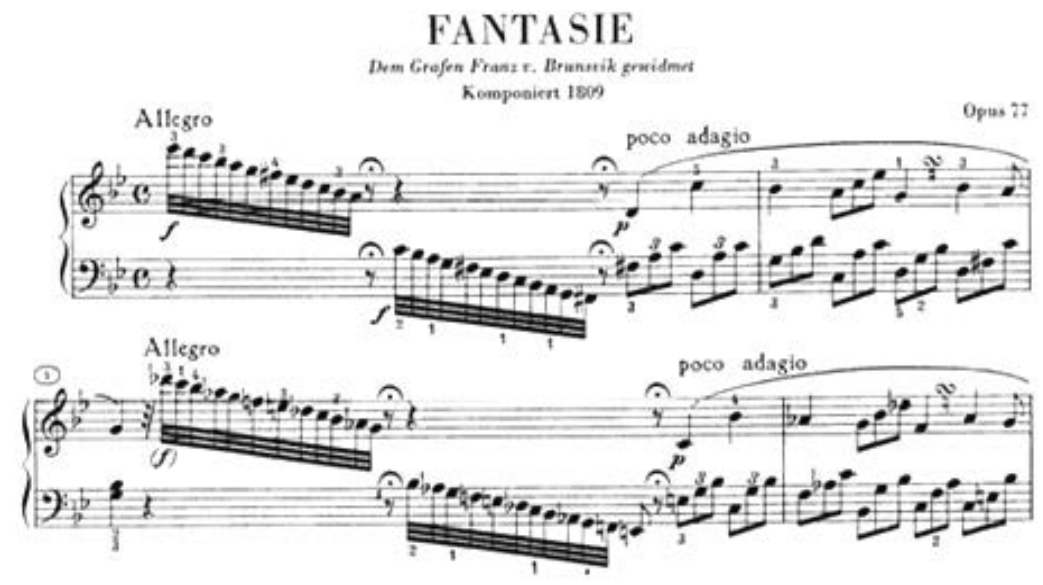

Example 10:
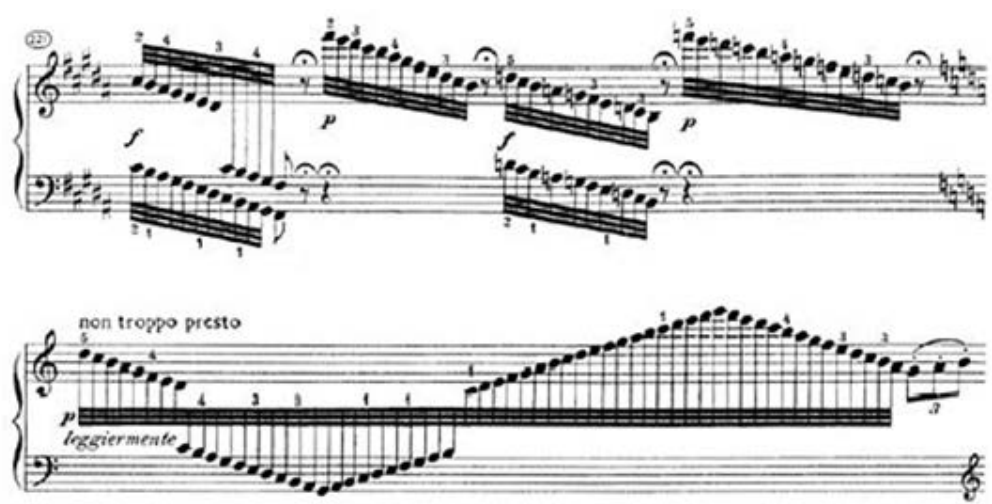

\subsection{Application of fermata in rest}

In the first, third, fourth, ninth and fourteenth bars, the fermata marked above the quaver rest seems to be the rest after "Beethoven speaks", which makes people memorable (see Example 9).

\subsection{Sharp continuous octave figure}

The allegro (from the $38^{\text {th }}$ bar to the $78^{\text {th }}$ bar) period full of vigor is inundated with saltatory interleaved decomposed octave figure. It is full of very strong dynamic sense.

Example 11:

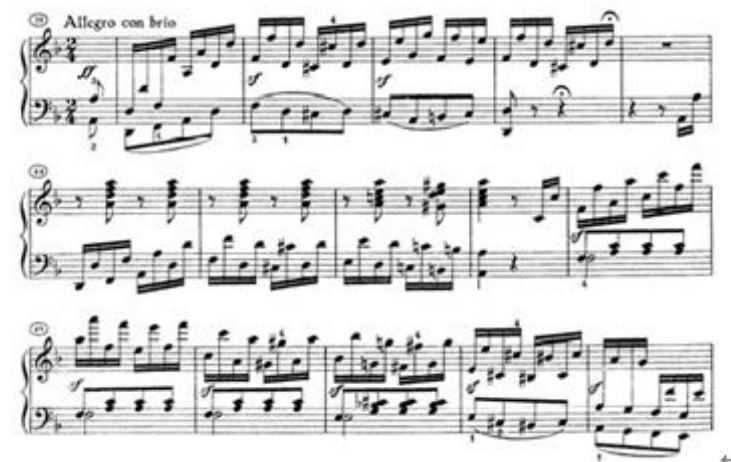

\subsection{Broken chord figure}

Broken chord figure is characterized by strong figure liquidity and fluent lyricism, so it is suitable for the periods with brisk chord rhythm and strong sense of rhythm. In the $38^{\text {th }}$ bar, coherent broken chord figure comes grandly, and is dazzling like the coloratura in the opera.

Example 12: 

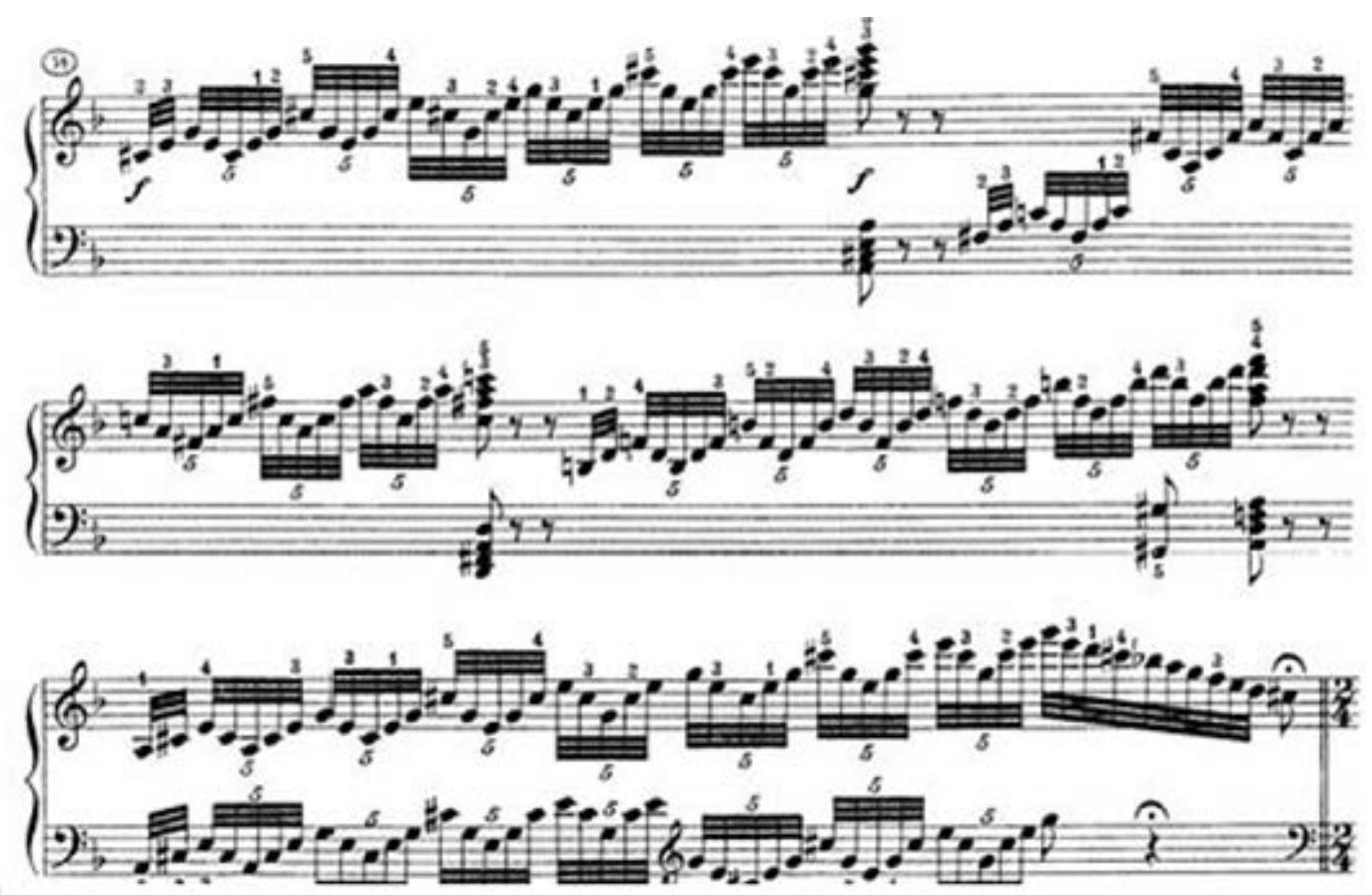

\subsection{Close collocation of low pith repeated melody and high pitch melody}

From the 101st bar to the 115th bar of G Minor Fantasia (OP.77), the low pitch repeated figure at the left hand is closely matched with flowing high pitch melody. The speed marked with Piú presto which is faster than presto increases the dramatic feeling of tension.

Example13:
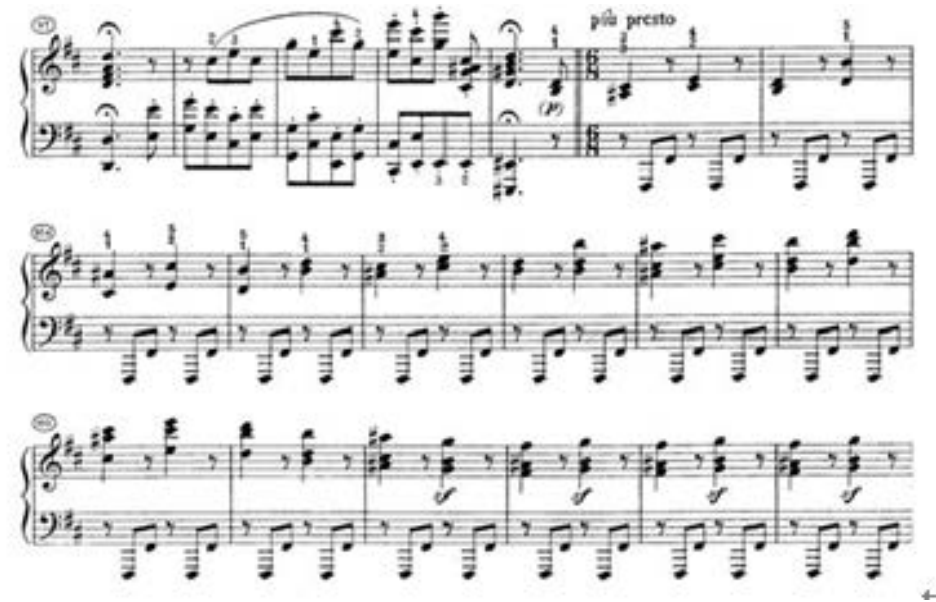

\subsection{Dynamics application}

In Beethoven's piano works, dynamics handling shows large contrast, multi-layer, fast frequency and fine handling in the gradual change process. This indicates Beethoven tried to expand the dynamics scope of piano sound. In the $37^{\text {th }}$ bard of $G$ Minor Fantasia (OP.77), the dynamics manifestation lies in the direct contrast between pp and ff. they are arranged on the ending chords of adjacent two periods. pp is marked under the primary chord of B-flat minor, while ff is marked under dominant seventh chord of D minor. Both of them have free fermata. In the beginning, the period shows positive pleasant mood. In the end, the dynamics gradually weakens to pp. The rhythm becomes slow from fast, and the texture becomes sparse from dense. The excited mood gradually becomes steady. It seems to let listeners be immersed in the fantastic imagination and make them have meaningful afterthoughts. Suddenly, an unstable dominant seventh chord is followed, which is performed by ff dynamics. This brings people unexpected amazing effect. Then, the dominant seventh chord becomes cadenza of fast and dense arpeggio figure. Under the insuppressible surprise, the passion is poured out (from the $31^{\text {st }}$ bar to the $37^{\text {th }}$ bar). 
Example 14:

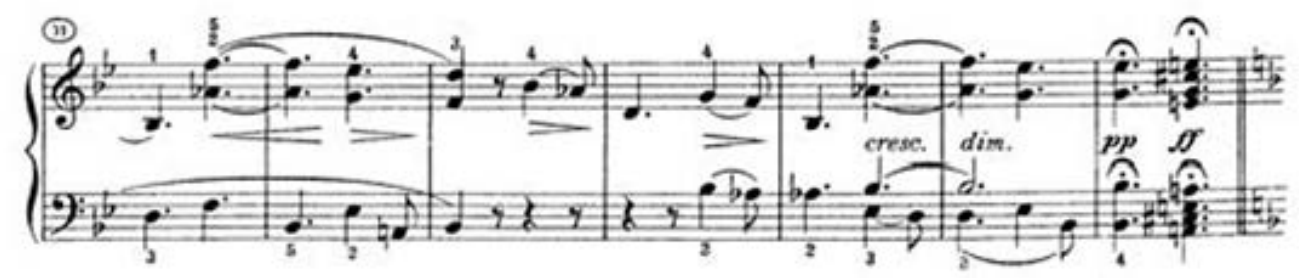

\subsection{Speed change}

Speed as one of important means can directly change music character. Speed will directly lead to character contrast. In this work, repeated speed transformation in the same movement is the innovation point of Beethoven. Allegro, Poco adagio and Listesso tempo make the work image no longer single, and the contrast is introduced.

Speed as one of important means can directly change music character. The speed contrast plays a very important role in expressing music character, content and mood. To keep the consistent music pattern and uniform music image, many musicians are very careful when handling the speed of music works. Especially in the movement, the speed will not be changed generally. But the change of speed in the same movement is the innovation point of Beethoven. In the first short 14 bars (Example 13), repeated speed transformation (Allegro, Poco adagio and Listesso tempo) makes work image no linger single, and the contrast is introduced. Such speed handling method is the herald of romantic composers' handling method.

Table 1. Speed mark of G Minor Fantasia (OP.77)

\begin{tabular}{|c|c|c|c|c|}
\hline Italian & Allegro & Poco adagio & Listesso tempo & Listesso tempo di sopra \\
\hline $\begin{array}{c}\text { Translated } \\
\text { term }\end{array}$ & 快板 & 稍慢板 & 等速 & 如同上面的速度 \\
\hline Italian & Adagio & Allegro con brio & Non troppo presto & Allegro,ma non trppo \\
\hline $\begin{array}{c}\text { Translated } \\
\text { term }\end{array}$ & 慢慢的 & 有活力的 & 急速但不要太多 & 快, 但不要过分 \\
\hline Italian & Presto & piú presto & Allegretto & Tempo primo \\
\hline $\begin{array}{c}\text { Translated } \\
\text { term }\end{array}$ & 急板 & 更急速的 & 小快板 & 恢复原速 \\
\hline
\end{tabular}

\section{Conclusion}

According to the above analysis, the work has quite many changes in terms of tonality, style, method, rhythm, texture and speed. The dramatic music is sometimes lively, sometimes dolorous, sometimes grand and sometimes high-spirited. Rich and varied tone forms continuously develop and change. The alternate appearance of different speed and figure shows opposite music individuality and music materials and also displays Beethoven's abundant music thinking and excellent creation ability. The theme continuously develops and varies, and the music is free, passionate, bold and unrestrained. It is a work full of fantasy and interestingness. The overall style of Beethoven's music is also embodied vividly in this work so that we feel his music language characteristics in the transition period from the middle age to the old age. The author hopes this paper can provide careful music analysis and the basis for piano performers to comprehensively understand the charm of Beethoven's "fantasia" art. 


\section{References}

[1] Yu Runyang, History of Western Music, Shanghai Music Publishing House, 2010.

[2] (American) Joseph Machlis, Appreciation of Western Music, translated by Liu Kexi, People's Music Publishing House, 1998.

[3] Li Jinzhu, Music Genius Beethoven, Shanghai Music Publishing House, 1997.

[4] (Australian) Carl Czerny, Correct Method to Perform Beethoven's All Piano Works, translated by Zhang Shuyi, Quanyin Yuepu Publishing House, 1986.

[5] (German) Felix Huch, Beethoven, translated by Sun Zeming, People's Music Publishing House, 1990.

[6] Oxford Simple Music Dictionary, People's Music Publishing House, 2002. 